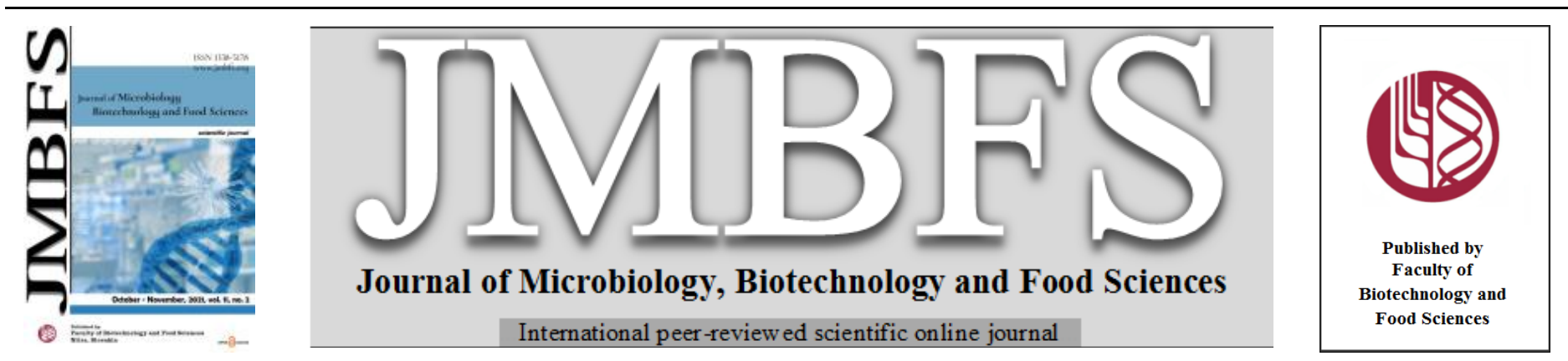

\title{
VISIBLE/NEAR-INFRARED (VIS/NIR) SPECTROSCOPY TECHNIQUE TO DETECT GRAY MOLD DISEASE IN THE EARLY STAGES OF TOMATO FRUIT
}

\author{
Khadija Njjar, Nawaf Abu-Khalaf* \\ Address(es): \\ Department of Agricultural Biotechnology, Faculty of Agricultural Sciences and Technology, Palestine Technical University-Kadoorie (PTUK), P.O.Box 7, Tulkarm, \\ Palestine
}

*Corresponding author: n.abukhalaf@ptuk.edu.ps

https://doi.org/10.15414/jmbfs.3108

ARTICLE INFO

Received 11.5. 2020

Revised 23. 4. 2021

Accepted 7. 5. 2021

Published 1. 10. 2021

Regular article

open $\partial_{\text {access }}$

\begin{abstract}
Fungal diseases are among the most common problems that affect tomato fruits, especially after harvesting. The early detection of these diseases may save $60 \%$ of the losses. Thus, this study aimed to detect the gray mold disease at an early stage on tomato fruits using the non-destructive visible/near-infrared (VIS/NIR) technique. Botrytis. cinerea fungus was isolated and identified using two specific primer sets (C729+/- and BC108+/BC563-). Three tomato varieties were used for this study (i.e. Harver, Izmer and Ekram), 30 samples from each variety, 20 samples were injected with the $B$. cinerea and 10 samples were left as control/healthy samples. Samples were examined using the VIS/NIR spectroscopy with a range of 550-1100 $\mathrm{nm}$ for three days. Thereafter, the data were analyzed using principal component analysis (PCA), where the results showed the ability of VIS/NIR to detect the infected samples on the second day of the injection, and before the symptoms appear on the samples. Two PCs explained $99 \%$ and 100\% of VIS/NIR variance, respectively.
\end{abstract}

Keywords: gray mold disease, visible/near-infrared (VIS/NIR) spectroscopy, early detection, multivariate data analysis (MVDA), principal component analysis (PCA)

\section{INTRODUCTION}

Plants are a basic food source for humans. Many fruits enter into the food industries that contribute to national income and it is important to achieve food security (Beghi et al., 2018; Ratnadass et al., 2012). Tomato (Solanum lycopersicum $L$.) is among the most important crops globally, which contributes to agricultural industries (Boriss \& Brunke, 2005). Where the area planted with tomato crops worldwide reached 4,850 million hectares, while the global production amounted to 3,700 tons per hectare $(\mathbf{F A O}, \mathbf{2 0 1 9})$. China is the highest producer of tomato, followed by The United States and India (Guan et al., 2018). However, plants, in general, are exposed to many diseases that affect their quantity and quality, causing economic losses (Khaled et al., 2018). Tomato crop, in particular, is subjected to many diseases, whether at pre-harvest or postharvest phases (Nabi et al., 2017). Gray mold disease caused by B. cinerea fungus is one of the most diseases that affect the quality of tomato fruits, especially during the post-harvest chain (Elad \& Shtienberg, 1995; Smith et al. 2014).

Many ways contribute to the detection of plant diseases, such as the naked eye or laboratory-based method (Kandpal \& Cho, 2014). However, these methods take time and mainly depend on the appearance of symptoms (Martinelli et al., 2015; Rizk, 2018). Therefore, it is necessary for early detection of the disease before symptoms appear to avoid economic losses, also to save the environment by reducing the using chemical pesticides (Alemu, 2015). For that reason, the trend is towards promising and alternative methods such as visible/near-infrared (VIS/NIR) technology for early detection of diseases (Saeys et al., 2019; Wu et al., 2008). The VIS/NIR technique is fast, accurate, non-destructive and it is a sensing technology that has already successfully managed to detect many plant pathogens before symptoms appeared (You et al., 2019).

The VIS/NIR spectroscopy principle is based on the vibration of particles for materials, as a result of energy absorption by the photon when the constituent bonds $(\mathrm{O}-\mathrm{H}, \mathrm{N}-\mathrm{H}$ and $\mathrm{C}-\mathrm{H})$ are exposed to the VIS/NIR spectrum (El-Mesery et al., 2019). It can be applied in three modes i.e. reflectance, interactance and transmittance mode (Nicolai et al., 2014). Usually, reflectance mode (R) is applied because it is considered the easiest method and has a high energy of $80 \%$ and later converted to absorption $(\log 1 / \mathrm{R})$ for fruit measurements (Zaid et al., 2020).

The spectra acquired from VIS/NIR spectroscopy need to be analyzed to extract useful information. Statistical methods, known as multivariate data analysis
(MVDA), are usually used to analyze spectra signals (Abu-Khalaf \& Hmidat, 2020). Principal component analysis (PCA) (Asitok et al., 2020), partial least squares (PLS) (He et al., 2005; Mudalal, 2020), linear discrimination analysis (LDA) (Wang et al., 2015) are important methods of analysis using MVDA. The PCA is a linear prediction method, which is applied to distinguish between samples. It consists of several principal components (PCs), the first PC has the most amount of information and the second follows and the latter PC carries the least amount of information (Farres et al., 2019).

The VIS/NIR technique has been tested in disease detection in several previous studies (Abu-Khalaf, 2015; Hahn, 2009; Liaghat et al., 2014). For example, Bienkowski et al. (2019) investigated the ability of VIS/NIR spectroscopy (400$1000 \mathrm{~nm}$ ) to detect late blight disease on potato plants and they could build a PCA model with an accuracy of $92 \%$ to distinguish between infected and healthy samples. Also, the VIS/NIR technology was used for a wavelength of 400-2500 $\mathrm{nm}$ to determine Aspergillus spp. on peanut leaf, and the results showed the ability of this technique to separate infected and uninfected samples using the LDA model with an accuracy of $86.4 \%$ of the variance (Shen et al., 2018).

To our best knowledge, there are no previous studies on the use of VIS/NIR spectroscopy $(550-1100 \mathrm{~nm})$ for detecting the gray mold caused by $B$. cinerea on tomato fruits. Therefore, this study aims to investigate the ability of VIS/NIR spectroscopy with a range of $550-1100 \mathrm{~nm}$ to detect $B$. cinerea fungus in tomato fruit at an early stage of infection.

\section{MATERIAL AND METHODS}

Isolation and identification of $B$. cinerea fungus

The $B$. cinerea fungus was isolated from infected tomato samples obtained from farms near Tulkarm, Palestine, and it was cultivated on potato dextrose agar (PDA). Several repeated isolates were made to obtain a pure sample of the fungus. After that, the plates were incubated for 14 days at $21 \pm 1^{\circ} \mathrm{C}$ for full growth (Dean et al., 2012). The fungus was identified morphologically based on the spore's shape and conidia's color using a light microscope. For this reason, a small piece of fungus was taken after 14 days of growth to prepare a microscopic slide and observed by a light microscope (Labomed, USA) (cat \# PN: 9135000901) (Williamson et al., 2007). 


\section{Molecular identification of $\boldsymbol{B}$. cinerea}

A Dneasy plant mini kit (Qiagen, Germany) was used for fungus DNA extraction. Almost 100-150 mg of freshly isolated B. cinerea fungus were scraped and placed in a $1.5 \mathrm{ml}$ tube. The tube's content was grinned by pellet pestles cordless motor (Sigma-Aldrich, Z359971-1EA, Germany) with $400 \mu$ lysis buffer and about $4 \mu 1$ Rnase. Then the tubes were placed in a water bath at $65^{\circ} \mathrm{C}$ for about $10 \mathrm{~min}$. After that, it was put in ice for $5 \mathrm{~min}$ after adding approximately $130 \mu \mathrm{l}$ of neutralization buffer. Afterwards, the tubes were centrifuged for $5 \mathrm{~min}$ on $14,000 \mathrm{rpm}$, then the supernatant was transferred to a new tube and added 1.5 of the transferred volume from the washing buffer. Then about $650 \mu \mathrm{l}$ was transferred to a $2 \mathrm{ml}$ collection tube and the content was centrifuged at 8,000 rpm for $60 \mathrm{sec}$. After that, 100-150 $\mu \mathrm{l}$ of elution buffer was added, and the tubes were left at room temperature for $10 \mathrm{~min}$. The total DNA was checked by gel electrophoresis (Rigotti et al., 2002). The C729+/- (forward: AGCTCGAGAGAGATCTCTGA) and (reverse:

CTGCAATGTTCTGCGTGGAA) specific primer set was used to produce 700750 bp in B. cinerea species (You et al., 2019). Besides, BC108F/BC563R (forward: ACCCGCACCTAATTCGTCAAC) and (reverse CTGCAATGTTCTGCGTGGAA) primer pair was used to amplify $600 \mathrm{bp}$ of DNA fragment for B. cinerea species (Fan et al., 2015). PCR was achieved in a $25 \mu 1$ reaction mixture for each primer set. The mixture contains $12.5 \mu 1$ of $2 \mathrm{X}$ GoTaqVR Green Master Mix (Promega Corporation, USA), $0.5 \mu$ l forward primer, $0.5 \mu \mathrm{l}$ reverse primer, $1 \mu \mathrm{l}$ fungal DNA and $10.5 \mu \mathrm{l}$ DNase free water (Biological Industries, USA). The DNA amplifications were done using a therma cycler (Verti ${ }^{\mathrm{TM}}$ 96, Applied Biosystems Company, USA), based on the following program, the denaturation cycle for $2 \mathrm{~min}$ at $95^{\circ} \mathrm{C}$, then 35 cycles of $45 \mathrm{sec}$ at $94^{\circ} \mathrm{C}$, the annealing step at $55^{\circ} \mathrm{C}$ for $50 \mathrm{sec}$ and $72^{\circ} \mathrm{C}$ for $50 \mathrm{sec}$, also for the final cycle the temperature was $72^{\circ} \mathrm{C}$ for 5 min (Gindro et al., 2005; Rigotti et al. 2006)

\section{Tomato samples}

Homogeneous and defects free tomato samples were collected from a farm in Tulkarm, Palestine. The samples were grown in optimal conditions in a greenhouse and were mature, suitable and ready to be sent to the local market. A total of 90 samples were obtained from three local varieties, which are Harver, Izmer and Ekram 30 samples per cultivar.

\section{Prepare a $B$. cinerea suspension}

According to Petrasch et al. (2019) protocol, a solution of $B$. cinerea fungus isolated after 14 days of growth was prepared by harvesting the spore using $\mathrm{KH}_{2} \mathrm{PO}_{4^{-}}$glucose solution, which consists of $0.5 \mathrm{~g}$ of $\mathrm{KH}_{2} \mathrm{PO}^{4}(10 \mathrm{mM}), 0.4 \mathrm{~g}$ of glucose $(10 \mathrm{mM})$ and $125 \mu \mathrm{l}$ of Tween- 80 for $250 \mathrm{ml}$. The concentration of spore suspension was set under the light microscope to reach $5^{*} 10^{4}$ spore per $\mathrm{ml}$ using the hematocytometer.

\section{Sterilization and injection of tomato samples by $\boldsymbol{B}$. cinerea suspension}

Tomato samples were sterilized with a $2 \%$ sodium hypochlorite $(\mathrm{NaOCl})$ solution, then washed with sterile distilled water and left to dry for an hour at room temperature $25 \pm 1{ }^{\circ} \mathrm{C}$ (Zhang et al., 2014). Then 20 samples of each variety were injected with a fungus solution with a $10 \mu \mathrm{l}$ of four areas around the neck region and 10 samples were left as a control and injected with a $0.05 \% \mathrm{KH}_{2} \mathrm{PO}_{4}$ glucose and tween 80 solution. After that, all samples were left at room temperature $25 \pm 1{ }^{\circ} \mathrm{C}$ with plastic boxes (Borges et al., 2014).

\section{VIS/NIR spectroscopy}

Spectra were taken from the zero-day to the second day of injection, using the VIS/NIR spectroscopy with USB2000+ (Ocean Optics, USA). An optical fiber with $50 \mu \mathrm{m}$ was used for connecting the reflectance vivo light through the samples. All data for the three days were recorded using Spectra Suite Software (Ocean Optics, USA). The integration time was $260 \mu$ s for all days. The spectra acquired by reflectance mode recorded as absorbance $\log (1 / \mathrm{R})$. To ensure the stability in spectra a reflectance standard (Ocean Optics, USA) was used every 10 minutes. Each sample is tested three times to confirm the spectra required.

\section{Data collection}

The data were collected using the Excel program (Microsoft office, 2013) and an average of 3 spectra per sample was calculated. After that, the data was analyzed using the Unscrambler (version 10.3, Camo Software AS, Oslo, Norway).

\section{Data preprocessing and analysis}

Savitzky-Golay (SG) smoothing to remove the spectra noise (Geladi et al., 1985) and the first derivative $\left(1^{\text {st }}\right.$ D) to increase spectrum resolution (Savitzky \& Golay, 1964) were applied for raw spectra. Principal component analysis (PCA) with test set validation was carried out for the spectra of samples during experiment days (i.e. zero-day, first day and second day of inoculation) to distinguish between healthy and infected samples using VIS/NIR region with a range of 550-1100 $\mathrm{nm}$. Where the measured samples were divided into 70 samples for calibration set and 20 samples for the validation set.

\section{RESULTS AND DISCUSSION}

\section{Identification of $B$. cinerea}

When identifying $B$. cinerea fungus morphologically, it was found that the obtained results are similar to those reached by Elad and Shtienberg (1995) and by Sharma and Pandey (2010) for B. cinerea identifying morphologically. Figure 1 shows the shape of fungal spores under the light microscope, also showing the conidia color of $B$. cinerea on PDA media.

The result of the PCR (700 bp) was also produced with a specific primer set C729+/- from isolated B. cinerea DNA. Moreover, 600 bp was produced by $\mathrm{BC} 108 \mathrm{~F} / \mathrm{BC} 563 \mathrm{R}$ specific primer pair confirmed that the isolated fungus was $B$. cinerea. These results are in agreement with the results reported by Rigotti et al. (2002) and by You et al. (2019) for using these primer sets to identify $B$. cinerea fungus. Figure 2 shows the PCR products.
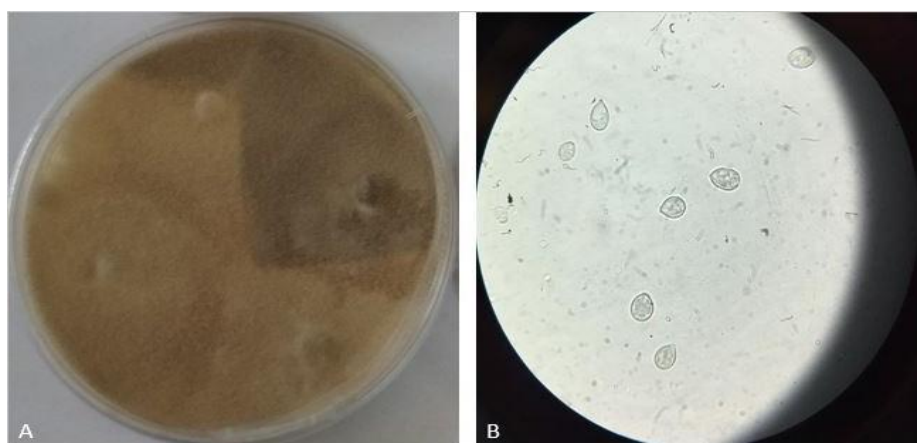

Figure 1 Morphological features of $B$. cinerea fungus cultured on PDA media for two weeks. A: pure fungal conidia grown on PDA media. B: fungal spores shape under a light microscope with an oil lens.

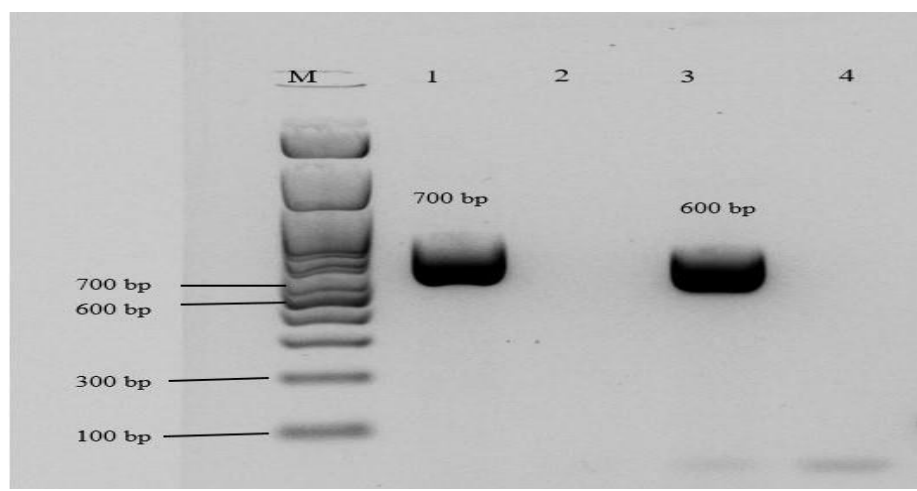

Figure 2 PCR product of $B$. cinerea DNA fungus with two specific primer pairs Lane 1: Lane specific primer set C729+/C729-. Lane 2: negative sample. Lane 3 specific primer set BC108+/BC563-. Lane 4: negative sample. M: 100 bp DNA marker ready to use (RTU).

\section{Spectral characterization}

The spectra were carried out for representative infected samples for all days (i.e. zero-day, the first day and second day of inoculation). When internal change occur as a result of the presence of the pathogen, the acquired spectra of the infected samples will be different from the healthy ones, which confirms that the VIS/NIR technique works as a fingerprint (Mahlein et al., 2010; Qu et al. 2015). This is what was observed when comparing between the measured spectra from the infected samples for all days, where there was no significant difference between the spectra of zero-day and the first day of injection, while there was a clear difference between the spectra of the first day and second day as shown in Figure 3. These results seem to be consistent with those published by Shen et al (2018) and Wu et al. (2008) which found that the spectra acquired from the infected sample differ from the healthy one.

After $1^{\text {st }} \mathrm{D}$ was carried out for representative spectra for infected samples as shown in Figure 4, the highest bands (i.e. peaks at 787, 948, 955 and $1081 \mathrm{~nm}$ ) in NIR region are likely the result of the high content of water $(\mathrm{O}-\mathrm{H})($ Rizk, 2018), while the highest band $(560 \mathrm{~nm})$ in VIS region is due to the presence of dyes (chlorophylls and carotenoids) and the lowest band $(983 \mathrm{~nm})$ in the second day of inoculation due to the consumption of carbohydrates $(\mathrm{C}-\mathrm{H})$ and proteins $(\mathrm{N}-\mathrm{H})$ 


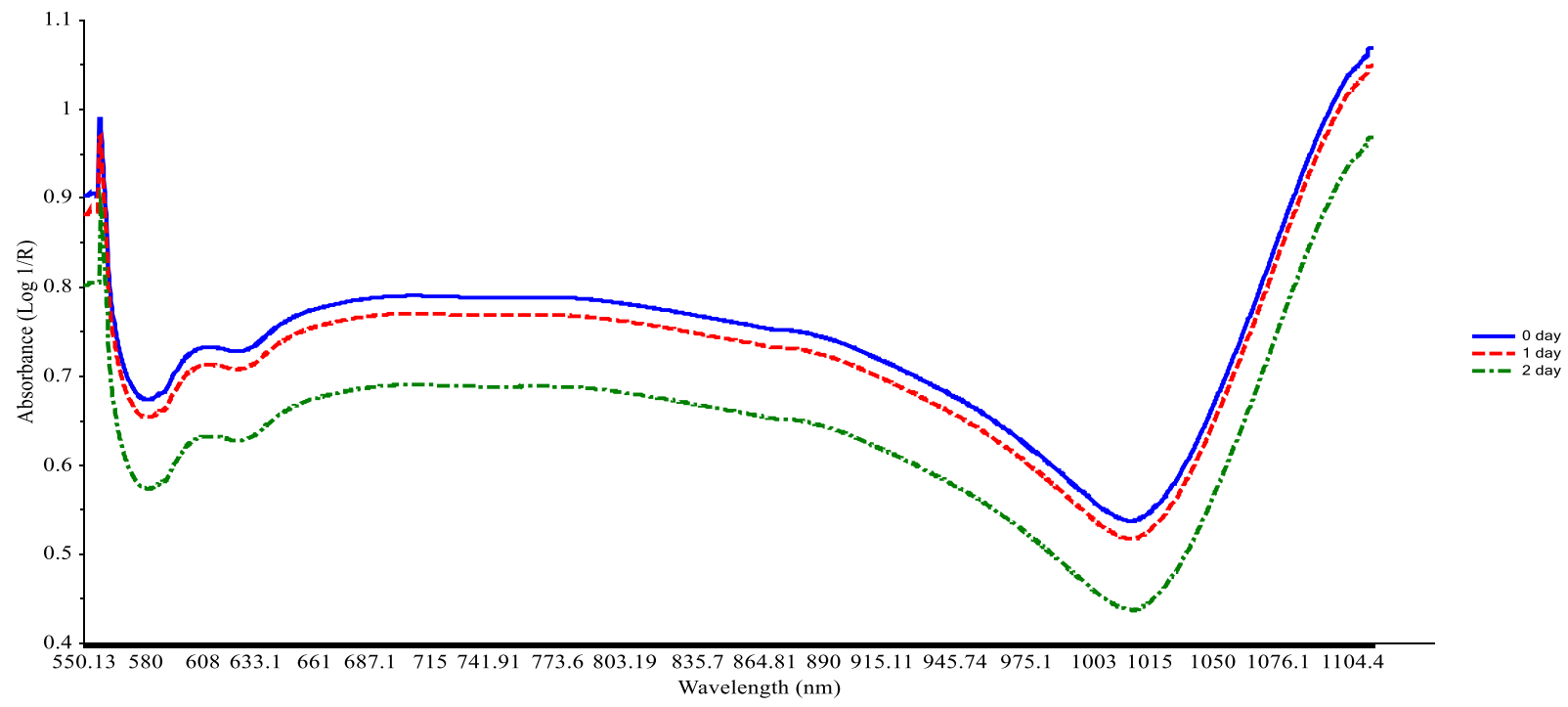

Figure 3 A representative VIS/NIR (550-1100 nm) spectral curve, with Savitzky-Golay (SG) smoothing effect, obtained from infected tomato samples. Zero-day (blue), the first day (red), the second day (green) of inoculation with gray mold.

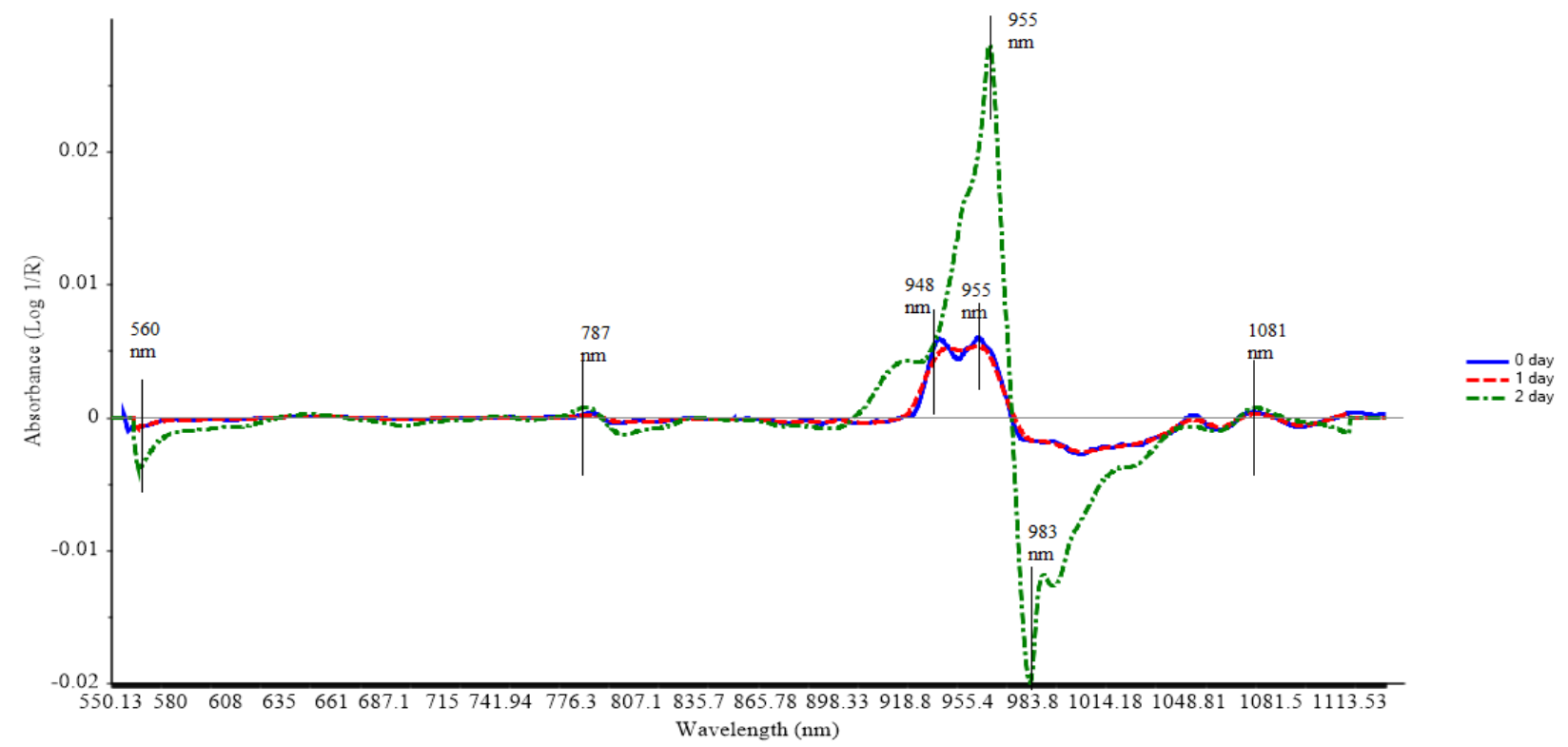

Figure 4 The effect of the first derivative $\left(1^{\text {st. }} \mathrm{D}\right)$ on the spectra obtained from the VIS/NIR region for infected samples. Zero-day (blue), the first day (red), the second day (green) of inoculation with gray mold.

\section{Principal component analysis (PCA) model}

PCA model with test set validation has been established for the average spectra of all samples during tested days. In the zero-day of injection, the PCA model was unable to separate infected and healthy samples as shown in Figure 5A and B. Where two PCs explained $83 \%$ and $82 \%$ of the total variance for calibration and validation set, respectively. While in the first day of injection, the PCA was able to distinguish between infected and healthy samples, with some overlapping, as shown in Figure 5C and D. Where two PCs explained $77 \%$ and $90 \%$ of the total variance for calibration and validation set, respectively. In the second day of injection, i.e. after $48 \mathrm{~h}$, the PCA was able to fully classify between infected and healthy samples with two PCs explained $99 \%$ and $100 \%$ of the total variance for calibration and validation set, respectively (Figure 6 and Figure 7).
Notwithstanding that the symptoms were not obvious with the naked eye at this stage.

The results showed the ability of VIS/NIR with a range of 550-1100 nm to discriminate the infected tomatoes from the no infected ones at the early stages of the gray mold disease. These results are in arrangement with several previous studies. Where Moscetti et al. (2015) investigated the ability of VIS/NIR spectroscopy with a range of $400-2500 \mathrm{~nm}$ to sense bactrocera olea that infested olive fruit and they could build a PCA model that explained $98 \%$ of the total variance for distinguishing between infected and healthy samples. In addition, Wu et al. (2008) tested the ability of VIS/NIR with a range of 400-1100 nm to sense $B$. cinerea fungus on eggplant leaves and could build a PCA model with an accuracy of $85 \%$ to classify the infected and healthy samples. 

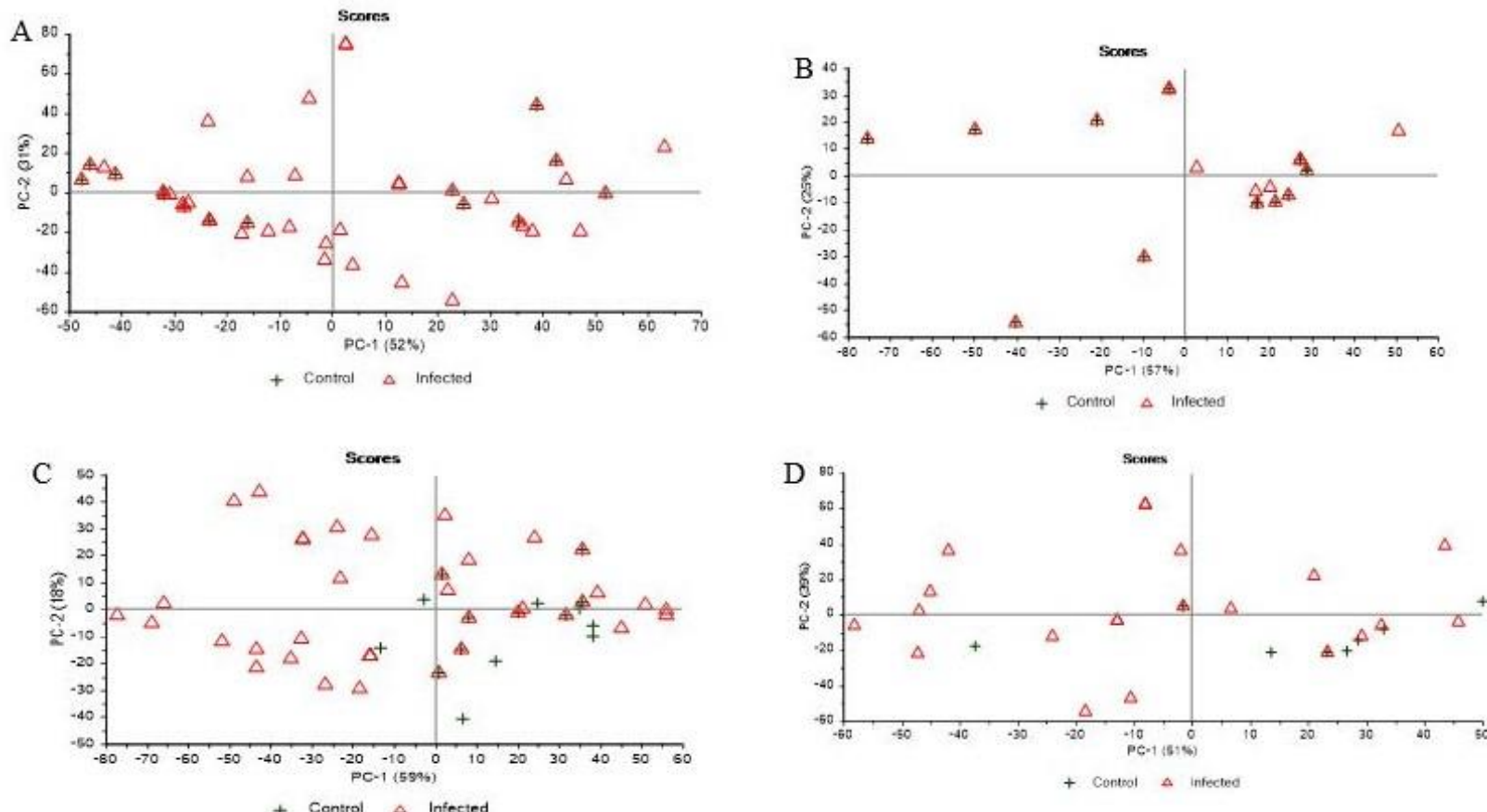

Figure 5 PCA model based on VIS/NIR (550-1100 nm) spectra. A. PCA model for calibration set (70 samples) for zero-day of inoculation with gray mold. Two PCs explained $83 \%$ of the total variance. B. PCA model for validation set (20 samples) for zero-day of inoculation with gray mold. Two PCs explained $82 \%$ of the total variance. C. PCA model for calibration set (70 samples) for the first-day of inoculation with gray mold. Two PCs explained $77 \%$ of the total variance. D. PCA model for validation set ( 20 samples) for the first day of inoculation with gray mold. Two PCs explained $90 \%$ of the total variance.

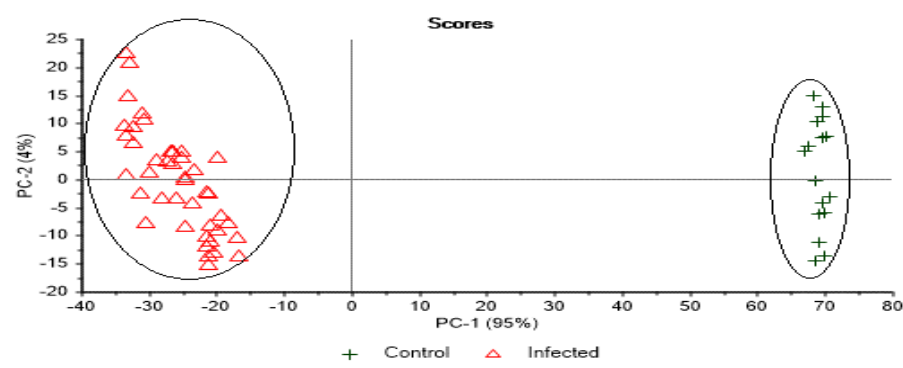

Figure 6 PCA model calibration set (70 samples) based on VIS/NIR (550-1100 $\mathrm{nm})$ spectra for the second day of inoculation with gray mold. Two PCs explained $99 \%$ of the total variance.

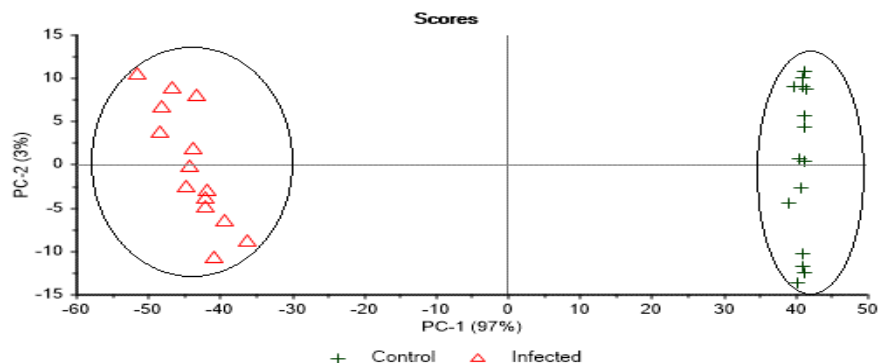

Figure 7 PCA model validation set (20 samples) based on VIS/NIR (550-1100 $\mathrm{nm})$ spectra for the second day of inoculation with gray mold. Two PCs explained $100 \%$ of the total variance.

\section{CONCLUSION}

The two primer sets (C729+/- and BC108+/BC563-) showed a high performance to identify $B$. cinerea fungus using the PCR method. Also, the PCA results showed the ability of VIS/NIR spectroscopy $(550-1100 \mathrm{~nm})$ to detect $B$. cinerea fungus on infected tomato fruit at an early stage. Furthermore, the result opens the way to use non-destructive portable VIS/NIR spectroscopy in food industries, as well as it can be used in the field and packaging houses to detect latent infection also to prevent the pathogen infection, and this can increase the safety of the products and reduce the economic losses. Further research is needed with other varieties and also demonstrate specificity with other pathogens.
Acknowledgment: The authors would like to thank Palestine Technical University-Kadoorie (PTUK) for funding the research through the master program of "Agricultural Biotechnology".

\section{REFERENCES}

Abu-Khalaf, N. \& Hmidat, M. (2020). Visible/Near Infrared (VIS/NIR) spectroscopy as an optical sensor for evaluating olive oil quality. Computers and

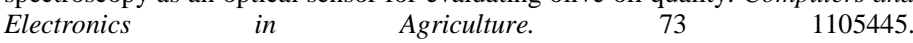
https://doi.org/10.1016/j.compag.2020.105445

Abu-Khalaf, N. (2015). Sensing tomato's pathogen using Visible/Near infrared (VIS/NIR) spectroscopy and multivariate data analysis (MVDA). Palestine Technical University Research Journal. 3(1), 12-22.

Alemu, K. (2015). Detection of Diseases, Identification and Diversity of Viruses: A. Journal of Biology, Agriculture and Healthcare. 5(1), 132-141.

Asitok, A., Ekpenyong, M., \& Antai, S. (2020). Multivariate Statistics of Fertility Parameter Fluxes in Cement-Dust-Polluted Soils in Mfamosing, Nigeria: Impact on Agriculture. Journal of Microbiology, Biotechnology and Food Sciences. 9(4), 781-789. https://doi.org/10.15414/jmbfs.2020.9.4.781-789

Beghi, R., Giovenzana, V., Tugnolo, A., \& Guidetti, R. (2018). Application of visible/near infrared spectroscopy to quality control of fresh fruits and vegetables in large-scale mass distribution channels: a preliminary test on carrots and tomatoes. Journal of the Science of Food and Agriculture. 98(7), 2729-2734. https://doi.org/10.1002/jsfa.8768

Bienkowski, D., Aitkenhead, M. J., Lees, A. K., Gallagher, C., \& Neilson, R. (2019). Detection and differentiation between potato (Solanum tuberosum) diseases using calibration models trained with non-imaging spectrometry data Computers and Electronics in Agriculture. 167 105056-105068. https://doi.org/10.1016/j.compag.2019.105056

Borges, A. V., Saraiva, R. M., \& Maffia, L. A. (2014). Key factors to inoculate Botrytis cinerea in tomato plants. Summa Phytopathologica. 40(3), 221-225. http://dx.doi.org/10.1590/0100-5405/1929

Boriss, H. \& Brunke, H. (2005). Commodity profile: tomatoes, fresh market University of California Agricultural Issues Center.

Dean, R., Van Kan, J. A., Pretorius, Z. A., Hammond-Kosack, K. E., Di Pietro, A., Spanu, P. D. et al. (2012). The Top 10 fungal pathogens in molecular plant $\begin{array}{llll}\text { pathology. Molecular Plant Pathology. 13(4), 414-430. } & \end{array}$ https://doi.org/10.1111/i.1364-3703.2011.00783.x

El-Mesery, H. S., Mao, H., \& Abomohra, A. E.-F. (2019). Applications of non destructive technologies for agricultural and food products quality inspection. Sensors. 19(4), 846-869. https://doi.org/10.3390/s19040846

Elad, Y. \& Shtienberg, D. (1995). Botrytis cinerea in greenhouse vegetables: chemical, cultural, physiological and biological controls and their integration Integrated Pest Management Reviews. 1(1), 15-29. https://doi.org/10.1007/BF00140331 
Fan, X., Zhang, J., Yang, L., Wu, M., Chen, W., \& Li, G. (2015). Development of PCR-based assays for detecting and differentiating three species of Botrytis infecting broad bean. Plant Disease. 99(5), 691-698. https://doi.org/10.1094/PDIS-07-14-0701-RE

FAO (2019). Statistical database of the FAO. Faostat [Electronic version]. Available: http://www.fao.org/faostat/en/\#data. Access date: 2/1/2020

Farres, S., Srata, L., Fethi, F., \& Kadaoui, A. (2019). Argan oil authentication using visible/near infrared spectroscopy combined to chemometrics tools. $\begin{array}{lll}\text { Vibrational } & \text { Spectroscopy. } & \text { 102(2019), }\end{array}$ https://doi.org/10.1016/j.vibspec.2019.04.003

Flores, K., Sanchez, M. T., Perez-Marin, D., Guerrero, J. E., \& Garrido-Varo, A. (2009). Feasibility in NIRS instruments for predicting internal quality in intact tomato. Journal of Food Engineering. 91(2), 311-318 https://doi.org/10.1016/j.jfoodeng.2008.09.013

Geladi, P., MacDougall, D., \& Martens, H. (1985). Linearization and scattercorrection for near-infrared reflectance spectra of meat. Applied spectroscopy. 39(3), 491-500. https://doi.org/10.1366/0003702854248656

Gindro, K., Pezet, R., Viret, O., \& Richter, H. (2005). Development of a rapid and highly sensitive direct-PCR assay to detect a single conidium of Botrytis cinerea Pers.: Fr in vitro and quiescent forms in planta. Vitis-Geilweilerhof 44(3), 139-143. https://doi.org/10.5073/vitis.2005.44.139-142

Guan, Z., Biswas, T., \& Wu, F. (2018). The US Tomato Industry: An Overview of Production and Trade. EDIS. 2018(2).

Hahn, F. (2009). Actual pathogen detection: sensors and algorithms-A review. Algorithms. 2(1), 301-338. https://doi.org/10.3390/a2010301

He, Y., Zhang, Y., Pereira, A. G., Gomez, A. H., \& Wang, J. (2005) Nondestructive determination of tomato fruit quality characteristics using VIS/NIR spectroscopy technique. International Journal of Information Technology. 11(11), 97-108.

Kandpal, L. M. \& Cho, B. K. (2014). A review of the applications of spectroscopy for the detection of microbial contaminations and defects in agro foods. Journal of Biosystems Engineering. 39(3), 215-226 http://dx.doi.org/10.5307/JBE.2014.39.3.215

Khaled, A. Y., Abd Aziz, S., Bejo, S. K., Nawi, N. M., Seman, I. A., \& Onwude, D. I. (2018). Early detection of diseases in plant tissue using spectroscopyapplications and limitations. Applied Spectroscopy Reviews. 53(1), 36-64 https://doi.org/10.1080/05704928.2017.1352510

Liaghat, S., Mansor, S., Ehsani, R., Shafri, H. Z. M., Meon, S., \& Sankaran, S. (2014). Mid-infrared spectroscopy for early detection of basal stem rot disease in oil palm. Computers and Electronics in Agriculture. 101 48-54. https://doi.org/10.1016/j.compag.2013.12.012

Mahlein, A. K., Steiner, U., Dehne, H. W., \& Oerke, E. C. (2010). Spectral signatures of sugar beet leaves for the detection and differentiation of diseases Precision Agriculture. 11(4), 413-431. https://doi.org/10.1007/s11119-010-9180-

Martinelli, F., Scalenghe, R., Davino, S., Panno, S., Scuderi, G., Ruisi, P. et al. (2015). Advanced methods of plant disease detection. A review. Agronomy for Sustainable Development. 35(1), 1-25. https://doi.org/10.1007/s13593-014-0246-

Moscetti, R., Haff, R. P., Stella, E., Contini, M., Monarca, D., Cecchini, M. et al (2015). Feasibility of NIR spectroscopy to detect olive fruit infested by Bactrocera oleae. Postharvest Biology and Technology. 99 58-62. https://doi.org/10.1016/j.postharvbio.2014.07.015

Mudalal, S., Zaid, A., Abu-Khalaf, N., Petracci, M. (2020). Predicting the quality traits of white striped turkey breast by visible/near infra-red spectroscopy and multivariate data analysis. Italian Journal of Animal Science, 19(1), 676-686. https://doi.org/10.1080/1828051X.2020.1779138

Nabi, S. U., Raja, W. H., Kumawat, K. L., Mir, J. I., Sharma, O. C., Singh, D. B. et al. (2017). Post harvest diseases of temperate fruits and their management strategies-a review. International Journal of Pure and Applied Bioscience. 5(3), 885-898. http://dx.doi.org/10.18782/2320-7051.2981

Nicolai, B. M., Defraeye, T., De Ketelaere, B., Herremans, E., Hertog, M. L., Saeys, W. et al. (2014). Nondestructive measurement of fruit and vegetable quality. Annual Review of Food Science and Technology. 5 285-312. https://doi.org/10.1146/annurev-food-030713-092410

Petrasch, S., Silva, C. J., Mesquida-Pesci, S. D., Gallegos, K., van den Abeele, C., Papin, V. et al. (2019). Infection strategies deployed by Botrytis cinerea, Fusarium acuminatum, and Rhizopus stolonifer as a function of tomato fruit ripening stage. Frontiers in Plant Science. 10 223-240. https://doi.org/10.3389/fpls.2019.00223

Qu, J. H., Liu, D., Cheng, J. H., Sun, D. W., Ma, J., Pu, H. et al. (2015). Applications of near-infrared spectroscopy in food safety evaluation and control: A review of recent research advances. Critical Reviews in Food Science and Nutrition. 55(13), 1939-1954. https://doi.org/10.1080/10408398.2013.871693

Ratnadass, A., Fernandes, P., Avelino, J., \& Habib, R. (2012). Plant species diversity for sustainable management of crop pests and diseases in agroecosystems: a review. Agronomy for Sustainable Development. 32(1), 273 303. https://doi.org/10.1007/s13593-011-0022-4

Rigotti, S., Gindro, K., Richter, H., \& Viret, O. (2002). Characterization of molecular markers for specific and sensitive detection of Botrytis cinerea Pers.:
Fr. in strawberry (Fragaria X ananassa Duch.) using PCR. FEMS Microbiology Letters. 209(2), 169-174. https://doi.org/10.1111/j.1574-6968.2002.tb11127.x

Rigotti, S., Viret, O., \& Gindro, K. (2006). Two new primers highly specific for the detection of Botrytis cinerea Pers. Fr. Phytopathologia Mediterranea. 45(3), 253-260. https://doi.org/10.14601/Phytopathol Mediterr-1833

Rizk, H. (2018). Automated early plant disease detection and grading system: Development and implementation. Master's Thesis. the American University in Cairo. https://fount.aucegypt.edu/etds/174

Saeys, W., Do Trong, N. N., Van Beers, R., \& Nicolai, B. M. (2019) Multivariate calibration of spectroscopic sensors for postharvest quality evaluation: A review. Postharvest Biology and Technology. 158 110981-111000. https://doi.org/10.1016/j.postharvbio.2019.110981

Savitzky, A. \& Golay, M. J. (1964). Smoothing and differentiation of data by simplified least squares procedures. Analytical chemistry. 36(8), 1627-1639.

Sharma, G. P. R. R. \& Pandey, R. R. (2010). Influence of culture media on growth, colony character and sporulation of fungi isolated from decaying vegetable wastes. Journal of Yeast and Fungal Research. 1(8), 157-164. https://doi.org/10.5897/JYFR.9000029

Shen, F., Wu, Q., Liu, P., Jiang, X., Fang, Y., \& Cao, C. (2018). Detection of Aspergillus spp. contamination levels in peanuts by near infrared spectroscopy $\begin{array}{llllll}\text { and } & \text { electronic } & \text { nose. } & \text { Food } & \end{array}$ https://doi.org/10.1016/j.foodcont.2018.05.039

Shen, F., Zhao, T., Jiang, X., Liu, X., Fang, Y., Liu, Q. et al. (2019). On-line detection of toxigenic fungal infection in wheat by visible/near infrared spectroscopy. LWT. 109 216-224. https://doi.org/10.1016/j.lwt.2019.04.019

Smith, J. E., Mengesha, B., Tang, H., Mengiste, T., \& Bluhm, B. H. (2014) Resistance to Botrytis cinerea in Solanum lycopersicoides involves widespread transcriptional reprogramming. BMC genomics. 15(1), 334-352. https://doi.org/10.1186/1471-2164-15-334

Wang, H., Peng, J., Xie, C., Bao, Y., \& He, Y. (2015). Fruit quality evaluation using spectroscopy technology: a review. Sensors. 15(5), 11889-11927. https://doi.org/10.3390/s150511889

Williamson, B., Tudzynski, B., Tudzynski, P., \& Van Kan, J. A. (2007). Botrytis cinerea: the cause of grey mould disease. Molecular Plant Pathology. 8(5), 561580. https://doi.org/10.1111/j.1364-3703.2007.00417.x

Wu, D., Feng, L., Zhang, C., \& He, Y. (2008). Early detection of Botrytis cinerea on eggplant leaves based on visible and near-infrared spectroscopy. Transactions of the ASABE. 51(3), 1133-1139. https://doi.org/10.13031/2013.24504

You, J., Guo, J., Yuan, Q., Guo, X., Gao, L., Duan, Y. et al. (2019). Botrytis cinerea causing grey mould on Epimedium brevicornum Maxim in China. $\begin{array}{llll}\text { Canadian Journal of Plant } & \text { Pathology. }\end{array}$ https://doi.org/10.1080/07060661.2019.1654546

Zaid, A., Abu-Khalaf, N., Mudalal, S., \& Petracci, M. (2020). Differentiation between Normal and White Striped Turkey Breasts by Visible/Near Infrared Spectroscopy and Multivariate Data Analysis. Food Science of Animal Resources. 40(1), 96-105. https://doi.org/10.5851/kosfa.2019.e88

Zhang, Z., Qin, G., Li, B., \& Tian, S. (2014). Infection assays of tomato and apple fruit by the fungal pathogen Botrytis cinerea. Bio-Protocol. 4(23), 1-5. https://doi.org/10.21769/BioProtoc.1311 